\title{
Biosimilars in Gastroenterology- An Important Moment in the Treatment of Inflammatory Bowel Diseases
}

\section{Grazyna Rydzewska ${ }^{1,2^{*}}$ and Michal Lipinski ${ }^{1}$}

${ }^{1}$ Gastroenterology Department, Central Clinical Hospital of the Ministry of the Interior and Administration, Warsaw, Poland

${ }^{2}$ Faculty of Medicine and Health Sciences, University of Jan Kochanowski, Kielce, Poland

Biological therapies, such as the monoclonal antibodies or soluble cytokine receptors have led to great improvements in the management of several immune-mediated inflammatory diseases including Crohn's disease and ulcerative colitis. Such therapies definitely can modify disease progression, resulting in a reduced need for corticosteroid use, a reduced hospitalization rate, a decreased need for surgery and an increased quality of life [1,2]. However until now high costs of biologics have also resulted in substantial financial burdens being placed upon individual patients and entire healthcare systems.

The use of antagonists of tumor necrosis factor (TNF- $\alpha$ infliximab, adalimumab, certolizumab and golimumab) has been shown to not only to induce and maintain clinical remission, but also lead to deep remission and a definite change to the IBD cure landscape [1,2], especially cases of inflammatory bowel diseases (IBD). However the patents and exclusivity for most biologics have either expired or will expire soon, thereby enabling biotechnological companies to introduce similar biological products. According to the definition proposed by experts from the European Medicines Agency (EMA), biosimilars are similar to other biological products that have already been approved, and do not have any significant differences from the reference product in terms of safety, physicochemical properties and efficacy [3]. Thus biosimilars are not a generic drug.

Recently in Europe, the patent of infliximab expired and the EMA has already approved a biosimilar of this medication on the European market. This was the first approval of a biosimilar of a complex molecule such as monoclonal antibodies. A biosimilar of infliximab (IFX) has been approved in many European countries for the same indications as the IFX counterpart, based on a single equivalence trial conducted in patients with rheumatoid arthritis [4]. From the outset, the possibility of replacing original drugs with biosimilars has raised hopes of lower treatment costs, which would enable the handling of more patients and their concerns. In the early stages of biosimilar use in gastroenterology, data of its efficacy and safety in IBD treatment was limited leading to concerns about indication extrapolation. Almost all gastroenterological societies believed that a bioequivalence study, restricted to rheumatoid patients, should be conducted independently in an IBD group.

With respect to biosimilar infliximab registration, the Working Group of the Polish National Consultant in Gastroenterology, in the absence of data regarding bioequivalence in patients with IBD, does not recommended replacing original biological medicine with its biosimilar analogue in the course of treatment [5]. Most clinicians argue against the interchangeability and automatic substitution of biosimilars [6] .

Currently, mostly retrospective data evaluating efficacy and safety of biosimilars in IBD have been published [7-9]. The first prospective randomized clinical trials were also recently published, but they are still limited $[10,11]$.

\section{Publication History:}

Received: November 16, 2016

Accepted: December 28, 2016

Published: December 30, 2016

\section{Keywords:}

Gastroenterology, Biosimilars, Inflammatory diseases , biological products

Our own centre's retrospective study concerning the efficacy and safety of a biosimilar of infliximab (Inflectra), in a cohort of 176 adult patients with Crohn's disease (CD) over one year of treatment followed by 6 months of observation, suggested similar results in efficacy and safety to a counterpart infliximab and adalimumab, not only in induction and one year CD therapy, but also during the 6-month follow-up [12]. Further retrospective data concerning the efficacy and safety of a biosimilar of infliximab in rescue therapy in the cases of 67 adult patients with severe ulcerative colitis (UC), suggested similar results in efficacy and safety compared to a counterpart infliximab, both in the rescue therapy of UC and during the 6-month follow-up [13].

Recently, the first interchange results in IBD were also published [14], showing that switching from Remicade to Remsima was feasible and with few adverse events, such as antidrug antibody formation and loss of response. Another important issue is the lack of long-term follow-up studies for efficacy and safety.

Taking all this into account, further prospective randomized studies for efficacy and safety, as well as immunogenicity and interchangeability with long-term follow-up periods are needed to confidently integrate biosimilars into IBD treatment, especially in terms of future registration of other biosimilars of TNF- $\alpha$ antagonists.

One last important issue, which I would like to discuss, involves changes in the knowledge of biosimilars amongst members of the European Crohn's Colitis Organization [ECCO] [15]. When comparing education among gastroenterologists in 2013 and 2016, the authors have concluded that knowledge about biosimilar use dramatically improved with new publications. Compared to 2013, there are now fewer concerns and more confidence about their use in clinical practice.

"Corresponding Author: Prof. Grazyna Rydzewska, Gastroenterology Department, Central Clinical Hospital of the Ministry of the Interior and Administration, Warsaw, Poland, E-mail: grazka3558@yahoo.pl

Citation: Rydzewska G, Lipinski M (2016) Biosimilars in GastroenterologyAn Important Moment in the Treatment of Inflammatory Bowel Diseases. In J Gastroenterol Disord Ther 3: 124. doi: http://dx.doi.org/10.15344/2393$8498 / 2016 / 124$

Copyright: (c) 2016 Rydzewska et al. This is an open-access article distributed under the terms of the Creative Commons Attribution License, which permits unrestricted use, distribution, and reproduction in any medium, provided the original author and source are credited. 
Citation: Rydzewska G, Lipinski M (2016) Biosimilars in Gastroenterology- An Important Moment in the Treatment of Inflammatory Bowel Diseases. Int J Gastroenterol Disord Ther 3: 124. doi: http://dx.doi.org/10.15344/2393-8498/2016/124

\section{Competing Interests}

The author(s) declare that they have no competing interests.

\section{References}

1. Park DI (2016) Current status of biosimilars in the treatment of inflammatory bowel diseases. Intest Res 14: 15-20.

2. Szymanska E, Dadalski M, Szymanska S, Grajkowska W, Pronicki M, et al. (2016) The impact of induction therapy with three doses of infliximab on deep histological healing in paediatric patients with active Crohn's disease. Prz Gastroenterology 11: 176-180.

3. Lee JF, Litten JB, Grampp G (2012) Comparability and biosimilarity: considerations for the healthcare provider. Curr Med Res Opin 28: 10531058.

4. Yoo DH, Hrycaj P, Miranda P, Ramiterre E, Piotrowski M, et al. (2013) A randomised, double-blind, parallel-group study to demonstrate equivalence in efficacy and safety of CT-P13 compared with innovator infiximab when co administered with methotrexate in patients with active rheumatoid arthritis: the PLANETRA study. Ann Rheum Dis 72: 1613-1620.

5. Mularczyk A, Gonciarz M, Bartnik W, Durlik M, Eder P, et al. (2014) Biosimilar medicines - their use in the treatment of inflammatory bowel diseases. Position statement of the Working Group of the Polish National Consultant in Gastroenterology. Prz Gastroenterol 9: 1-3.

6. Teixeira FV, Kotze PG, Damiăo AO, Miszputen SJ (2015) Biosimilars in inflammatory bowel diseases: an important moment for Brazilian gastroenterologists. Arq Gastroenterol 52: 76-80.

7. Park SH, Kim YH, Lee JH, Kwon HJ, Lee SH, et al. (2015) Post-marketing study of biosimilar infliximab (CT-P13) to evaluate its safety and efficacy in Korea. Expert Rev Gastroenterol Hepatol 9 Suppl 1: 35-44.

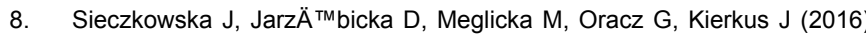
Experience with biosimilar infliximab (CT-P13) in paediatric patients with inflammatory bowel diseases. Therap Adv Gastroenterol 9: 729-735.

9. Jung YS, Park DI, Kim YH, Lee JH, Seo PJ, et al. (2015) Efficacy and safety of CT-P13, a biosimilar of infliximab, in patients with inflammatory bowel disease: A retrospective multicenter study. J Gastroenterol Hepatol 30: $1705-1712$

10. Gecse KB, Lovász BD, Farkas K, Banai J, Bene L et al. (2016) Efficacy and Safety of the Biosimilar Infliximab CT-P13 Treatment in Inflammatory Bowel Diseases: A Prospective, Multicentre, Nationwide Cohort.J Crohn's Colitis.10: 133-140.

11. Farkas K, Rutka M, Golovics PA, Végh Z, Lovász BD, et al. (2016) Efficacy of Infliximab Biosimilar CT-P13 Induction Therapy on Mucosal Healing in Ulcerative Colitis. J Crohns Colitis 10: 1273-1278.

12. Kaniewska M, Rydzewska G (2016) P519 Efficacy and safety of biosimilar of infliximab (Inflectra)in adult patients with Crohn disease during one year of the treatment followed 6 months of observation - one center retrospective study. J Crohn's Colits 10: S363.

13. Kaniewska M, Rydzewska G (2016) P645 Efficacy and safety of biosimilar of infliximab in rescue therapy in adult patients with severe ulcerative colitis. J Crohn's Colitis 10: S428.

14. Buer LC, Moum BA, Cvancarova M, et al. (2016) Switching from Remicade $₫$ to Remsima $₫$ is well tolerated and feasible: a prospective, open-label study. J Crohns Colitis.

15. Danese S, Fiorino G, Michetti P (2016) Changes in Biosimilar Knowledge among European Crohn's Colitis Organization [ECCO] Members: An Updated Survey. J Crohns Colitis 10: 1362-1365. 